\title{
Observations of Boring Behaviour and the Drilling Mechanism of Lunatia fortunei (Gastropoda: Naticidae) in Western Korea
}

\author{
Ee-Yung Chung ${ }^{1}$, Sung Han $\mathrm{Kim}^{2}$, Yong Hae Back ${ }^{3}$ \\ ${ }^{1}$ Korea Marine Environment \& Ecosystem Research Institute, Dive Korea, Bucheon \\ 420-857, Korea \\ ${ }^{2}$ Department of Aquaculture and Aquatic Science, Kunsan National University, Gunsan 573-701, Korea \\ ${ }^{3}$ Wetlandkorea Instittute, Incheon 417-841, Korea
}

\begin{abstract}
Boring behaviour and drilling mechanism were investigated by visual observations. In this study, of two kinds of holes (the outer and inner holes) which are formed by drilling of boring gastropod Lunatia fortunei (Naticidae), the diameters of the outer holes are broader and larger than those of the inner holes, and their holes look like the crater in shape, as seen in all valves of bivalves bored by Naticidae species. Two kinds of glands (the accessory boring gland and accessory salivary gland) on the foots of boring gastropods have been investigated. Of them, it has been confirmed that only the accessory salivary glands on the foots secreted sulphuric (acidic) components in the mucus (secretion), while the accessory boring glands on the foots did not secrete their components. In this study, we confirmed that $L$. fortunei possess the accessory boring gland on the foot, as seen in most species in Naticidae. Accoeding to the results of the experiment of the blue litmus paper tests of the mucus (secretions) secreted from the accessory boring gland the color of the blue litmus paper did not turn red in color because chemical components of mucus (secretion) secreted from the accessory boring gland on the foot of $L$. fortunei (boring gastropod) were not acidic components. It is supposed that the mucus, which is secreted from the accessory boring gland, contained gelatin-like substances or enzymes without acidic components, as already reported in Naticidae species. Therefore, these substances may be involved in softening the surface of the valves of $M$. veneriformis. Consequently, it is assumed thar $L$. fortunei bores holes through the shells of molluscs by means of following 3 methods: (1) a softening of the calcareous shells of $M$. veneriformis with chemical secretions (including gellatin-like substances or enzyme except for acidic components) from the accessory boring glands, (2) mechanical rasping with the radula, (3) a combination of both. In this study, particularly, acidic components, which are involved in softening the surface of the shells, are not associated with the boring mechanism of $L$. fortunei because chemical acidic components were not detected in the mucus (secretion), as found in Naticidae species.
\end{abstract}

Keywords: Lunatia fortunei, Boring Behaviour, Drilling Mechanism

\section{INTRODUCTION}

The fortune's moon snail, Lunatia fortunei is one of the edible gastropods in East Asian countries, including Korea, China, and Japan (Kwon et al., 1993; Min et al., 2004). More specifically, in Korea, this

Received September 21, 2011 ; Accepted September 28, 2011

Corresponding author: Ee-Yung Chung

Tel: +82 (32) 328-5145 e-mail: eychung@kunsan.ac.kr $1225-3480 / 24402$ species is mainly found in the silty sand at the intertidal zone of the south and west coasts of Korea. In the shellfish aquafarms, it was occassionally found that boring snail Lunatia fortunei (Naticidae) attacks and bores the valves of some bivalves such as Crassostrea gigas and Mactra veneriformis, and then this species obtains food through holes drilled by them in the calcareous exoskeletons of preys. For that reason, it is well-known that Lunatia fortunei is canivorous snail and called as one of the harmful organisms in the shellfish aquafarms. Above all, it is 
important to get some information on feeding ecology associated with boring behaviour and the drilling mechanism of this species.

Previously, there have been many studies on aspects of reproduction, including reproductive ecology (Amio, 1963), on aspects of classification, including nomenclatorial note (Habe, 1969) and catalogue and biography of classification (Higo et al., 1999), and on the aspect of ecology, including distribution, habitat (Kwon et al., 1993) and feeding (Hong et al., 2006) of this species.

To date, there have been many studies on boring behaviour and boring morphology of boring gastropods. In particular, regarding various kinds of boring gastropods, there were many studies on boring gastropods, including boring behaviours of Neverita didyma (Tamura, 1960), Natica janthostoma (Choi, 1962), Tectonata janthostomoides (Hamada, 1961) and Metrix lusoria (Lee, 1969). And some gastropods were reported: oyster drill of $C$. virginica by prosobranch (Carriker, 1943) and common oyster drill of Urosalpinx cincrea (Carriker, 1943).

The drilling process has not been observed directly and its process is hidden (Turner, 1953). Fisher (1922) obtained a reddening of blue litmus paper when touched to fresh pads and concluded that the hole is dissolved with acid secreted by this organ which he named the "boring gland'. However, Pelsceneer (1925) reported that the salivary secretions contain no acid and concluded that drilling process is purely mechanical.

However, many researchers have still believed that G. didyma didyma and Naticidae species secrete sulphuric acid components and gelatin-like substances from the boring gland, and then these gastropods (predators) make a drilled hole on the valves of prey (bivalves) by mechanical rasping with the radula. However, Turner (1953) supposed that Naticidae species do not secrete sulphuric acid from the boring gland, and drill hole by mechanical rasping with the radula of the snail, and the radular is involved in the formation of a drilled hole on the valve of the prey. In case of this species and Naticidae species, it has been confused whether their secretions, which are secreted from the accessory boring gland, contain sulphuric

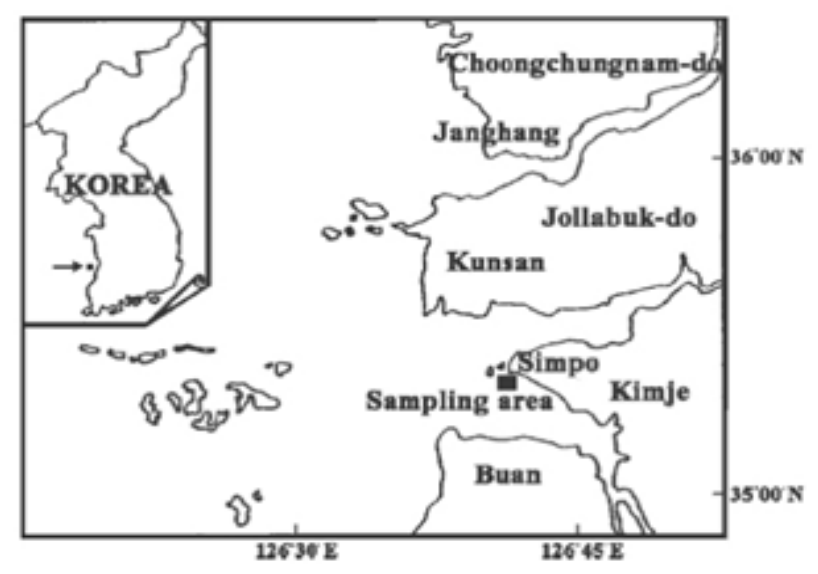

Fig. 1. Map showing the sampling area.

acid or not? Recently, the boring mechanism by penetration is incompletely understood. Therefore, it is important to check chemical components of secretions from boring gland of this species. In adition, it is also important to study boring behaviour and drilling mechanism. The purpose of the present study is to clarify and describe boring behaviour and drilling mechanism of this species.

\section{MATERIALS AND METHODS}

\section{Sampling Methodology}

Specimens of the moon snail, L. fortunei (Naticidae) were collected monthly in the intertidal zone of Simpo, Korea, from May to August, 2006 (Fig. 1). A total of 153 moon snails ranging from $49-52 \mathrm{~mm}$ in shell height (28-30 $\mathrm{mm}$ in width) were collected during the period of the study. Of them, 58 moon snails were transported alive to the laboratory for the indoor experiments, and each individual shell height was measured.

\section{Observations on Boring Behaviour, the holes on the valves of $M$. veneriformis by boring snail, $L$. fortunei.}

\section{1) Field experiments in the shellfish aquafarm}

\section{(1) Boring behaviour}

For preparing for the out door experiment on boring behaviour, a total of 153 specimens of $L$. fortunei were found from May to August 2006. In the field experiment at the shellfish aquafarm, special behaviour characteristics for predation of the 


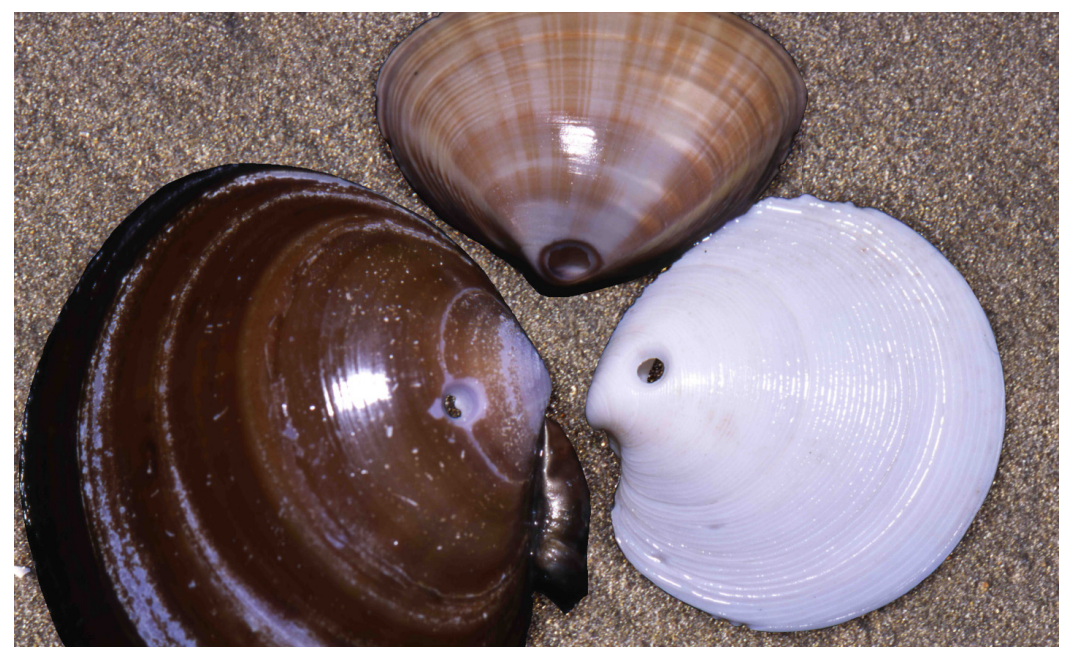

Fig. 2. A photograph showing the boring holes drilled on the valves of three kinds of bivalves by boring gastropods in the shellfish farms. Upper; Mactra chinensis, Low, left; Nuttallia Japonica, right; Phacosoma japonicus.

predator, L. fortunei were investigated and recorded by time. In the field experiments, ecological characteristics of capture behavour of $L$. fortunei were investigated.

A total of 85 Mactra veneriformis of $30.3-33.5 \mathrm{~mm}$ in shell height were collected in the shellfish aquafarm, and they were investigated to clarify their morphological characteristics of the outer and inner holes of Mactra veneriformis drilled by $L$. fortunei.

(2) Eexperiment on detection of chemical components in the mucus in the shellfish aquafarm

A total of 53 moon snails of $25.2-32.7 \mathrm{~mm}$ in shell height, which were found in the aquafarm, and they were used for the detection of chemical components of the valves were damp with the mucus of secretions secreted from the accessory boring gland on the foot of L. fortunei by blue litmus paper test. To clarify the boring mechanism between predator and prey, the blue litmus papers were touched to around parts of the holes on the valves in the field.

\section{Indoor experiments in the laboratory}

Sometimes, for observations of boring behaviours of the boring gastropod L. fortunei, we carried out the indoor experiment, and observed boring behavior of some snails in detail in the an aquarium in the laboratary. We observed boring behaviours, the morpholologies and size differences of boring holes (inner and outer holes) and detection of chemical components in the mucus in the aquariums.

\section{RESULTS}

\section{Observations of Boring Behaviour of the boring snail $L$. fortunei}

In general, the holes on the died valves of bivalves such as Mactra chinensis, Nuttalia japonica, Phacosoma japonicus, and by boring gastropod, Glassaulax didyma didyma were very easily found in the shellfish aquafarm (Fig. 2), while it is hard to find the holes on the died valves of bivalves such as $M$. veneriformis by the boring snail, $L$. fortunei in the shellfish aquafarms. In this study, occassionally, we observed boring behaviour of the boring snail $L$. fortunei as follows.

As soon as predator, L. fortunei (Gastropoda: Naticidae) touched the shell of prey, the predator attached on the valve of $M$. veneriformis (prey) in the field of shellfish aquafarm. And then the predator secreted mucus from its pedal part in order to prevent the prey from escaping by covering with secretion (Fig. 3). One hour later, the predator creeped into the bottom sand and bury itself accompanying with prey (M. veneriformis). After 2.3 hours more, boring was completed, and a small circular hole (being composed of the outer and inner 


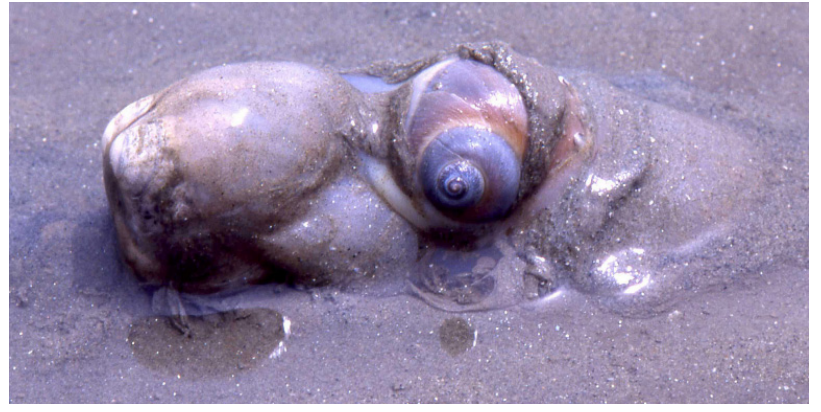

Fig. 3. The surf clam (Mactra veneriformis) captured by the boring gastropod Lunatia fortunei showing boring behaviour for feeding in the shellfish farm.

holes) was left on the right or left valves of the clam. In the field, the morphology of the holes was crater-like in shape (Fig. 4). For observations of the processes of boring behaviour and drilling mechanism in the indoor experiments, after 30 individuals of Lunatia fortunei were collected in the fields, predators were transported alive to several aquariums at the laboratory. and several predators attached on the valves of preys in the aquarium.

In the field experiment, we could catch several good phenomena associated with boring behaviour as follows. For one minute, the predator attached on the valve of $M$. veneriformis by umbonal region where boring gland was located. And then, umbonium region was replaced by odontophore, scraping of the radula and jaw-plates could not observe in detail on the valve surface of the prey because the secretions covered up the the radula and jaw-plates. The hole was completed and widened by such shifts of two processes of operations. And then the mouth is structurally changed and the flesh (meat) of prey was absorbed into the mouth of the predator.

\section{Experiment on morphological characteristics of the holes on the valves of $M$. veneriformis by $L$. fortunei in the aquaria}

Observations of corelationships between a number of $M$. veneriformis (prey) and several predators were carried out in the aquaria with sands. After boring holes completed, the kinds and morphologies of holes on the valves of $M$. veneriformis drilled by $L$. fortunei were two kinds of holes (inner and outer holes) and crater in shape, respectively. In general, the sizes of

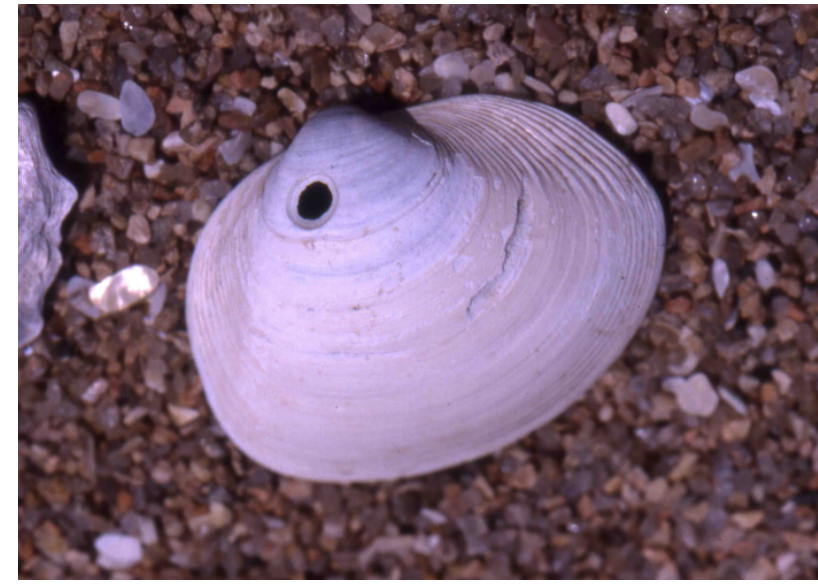

Fig. 4. A boring holes drilled on the valves of Mactra veneriformis in the shellfish farms.

outer holes were larger than those of the inner ones (Fig. 4). The morphology of the holes are craft in shape.

\section{Confirmation of lack of acidic components in secretions (mucus) secreted by boring snail around the incompleted hole}

A living clam ( $M$. veneriformis) which were attached to the foots of boring snail (L. fortunei) was found in the sand in the field of shellfish aquafarm, A living clam (M. veneriformis) attaching to boring snails was digged out from the sand with bare hands. The results of the field experiments and observations are as follows. Whenever each living clam was took out from the foot of each boring gastropod, an uncompleted hole on the valve of $M$. veneriformis was found during the period of formation of the hole. At that time, each valves of clams was wet with the mucus in secretions secreted from the accessory boring gland (ABO) of the snail. When blue litmus papers immedietely touched to near the hole which was wet by secretion, at that time, the color of the blue litmus paper did not turn red because chemical components of secretions were not acidic component. It is assumed that the mucus in the secretion, which is secreted from the accessory boring gland ( $\mathrm{ABO}$ ), may be, contains gelatin-like substances or enzymes, as reported in other Naticidae species. Therefore, we supposed that some components in these secretions may be involved in softening the surface of the valves of clams. 


\section{Drilling Mechanism of $L$. fortunei}

Regarding boring mechanism of the boring snail, $L$. fortunei, above all, it is very important to investigate various kinds of organs existed on the foot of boring species. There are two kinds of glands such as accessory boring gland and accessory salivary gland on the foot of boring gastropods. however, these organs on the foot of boring snails vary with the species in the family. In case of $L$. fortunei, and Naticidae species (L. lewisi, Natica severa, Polinices duplicatus, Sinum perspectivum), accessory boring organs are present, however, accessory salivary glands are lacking. Drilling process is purely mechanical. In this study, there is no evidence that acid contents were not detected in the mucus secreted from the accessory boring glands when the blue litmus paper touched to the mucus of secretions on the valves of M. veneriformis. This species drills holes through the shells of their prey by only mechanical rasping with the radula, particular unaided by chemical secretions.

\section{Indoor experiments in the aquarium in the laboratory}

The results in the door experiments were similar to those of the field experiments, including 1) boring behaviours, 2) the size and morphological differences of the inner or outer holes, 3) lack of acidic components in secretions (mucus) secreted by the boring snail, and 4) final confirmations of the boring mechanism.

\section{DISCUSSION}

\section{Boring behaviour and drilling mechanism}

Of carnivorous gastropods, Buccinidae species belong to non-boring predatory snails such as Bussinum undatum and Neptunea decemcostata lack both the accessory boring organ and the accessory salivary gland, and their proboscies and radula are equipped for tearing, and pulling flesh rather than for rasping shell.

For boring of the valves of the prey ( $M$. veneriformis), the predator creeped into the bottom sand and buried itself accompanying with prey. After 2.3 hours more, boring was completed, and each circular hole (being composed of the outer and inner holes) was left on the right or left valves of the clam. The morphology of the holes was crater-like shaped, and the outer holes were larger than the inner holes. These phenomena appearred by boring gastropods occasion- ally were found in young bivalves of Tapes philippinarum (Choi, 1962) and those of Meretrix lusoria. Carriker (1961) reported that experimental studies by several researchers on boring mechanism in naticid, muricid, and thaidid, prosobranch gastropods contributed further information on boring mechanism and support a chemo-mechanical theory of penetration in which abrasive action of the radula removes shell softened by secretion from the accessory boring organ (ABO).

According to the kind of glands on the foot of carnivorous boring gastropods, in general, there are two kinds of glands such as accessory boring gland and accessory salivary gland, the presence of these organs on the foot of boring gastropods vary with the species in the family.

Carriker (1961) also described that the accessory boring organ $(\mathrm{ABO})$ is present in 29 species of boring species examined: under the distal tip of the proboscis in 5 Naticidae, and in the sole of the foot of 24 Muricidae and Thaididae. Regarding Muricidae, Carriker (1961) also reported that in Thais clavigera, T. h. haysae, Rapana thomasiana, the accessory boring organ lies at top. And also in Murex brevifrons, $M$ cellulo, M. fulvescens, M. pomum, Muricopsis ostrearum, Ocenebra erinacea., O. japonica, Pterorytis foliata, T. deltoydia, T. amarginaa, T. lamellosa, T. lustica, the accessory boring organ appears as a separate organ in the anterior mid-ventral portion of the foot. However, he stated that Murex pomum did not contain the accessory salivary gland. Exceptionally, Graham (1941) reported that secretion of the accessory salivary glands of Thais lapillus has a $\mathrm{pH}$ of 6 and does not each shell or dissolve shell flakes.

Fischer (1922) reported that hole is bored mechanically with the radula working as a rasp, however, he suggested that its action might be facilitated by a softening of the calcareous shells with sulphuric acid secreted by the salivary glands. 
However, Pelsceneer (1925) stated that the salivary gland secretions contained no acid and concluded that drilling process was purely mechanical. In this study, acid components were not detected in the mucus in the secretion secreted from the accessory boring glands when the blue litmus paper touched to the mucus of secretions on the valves of $M$. petechialis. However, in case of the exsistence of of some acidic components in the secretions, it is assumed that boring mechanism of boring gastropods drill holes through the shells of other molluscs by means of following 3 methods proposed by Turner (1953): (1) chemical secretions from the salivary glands or similar organs, (2) mechanical rasping with the radula, or similar organs, (3) a combination of both.

Colton (1908) suggests that the snail waits until the oyster opens and then inserts its shell between the valves. The ventral surface of the foot of the snail secretes a highly viscous mucus. There were the experiments to determine the ability of the Naticidae to drill through other inert materials, two experiments were performed with the American clam drill, Polynices duplicata, to test ability to perforate lamellibranch shells coated with paraffin wax and plaster of Paris.

According to Carriker (1951), when a number of clams (Mya arenaria) coated with histolological paraffin in layers approximately $0.5 \mathrm{~mm}$ thick, were placed in a seawater aquarium containing starved P. duplicata, the polynices readily attacked the coated clams and drilled typical holes without any interference from the wax layers. This established the fact that the drilling processes basically mechanical but did not preclude auxiliary use of chemical secretions to soften the hard calcareous shell after the wax had been scraped away. The Polynices readily attacked clam coated with Plaster of Paris and drilled typical holes through the coatings without apparent difficulty. Therefore, on the whole, I agree with Carriker's (1951) opinions mentioned above.

The function of the so-called boring gland (ABO) is not apparent, but its structure and location suggested that it may be an adhesive pad that holds the anterior extremity of the proboscis firmly against the shell to facilitate the action of the radula. Therefore, this species drills holes through the shells of other molluses by means of following 3 methods: (1) a softening of the calcareous shells of the prey with chemical secretions (including gellatin-like substances or enzyme except for acidic components) from the accessory boring glands, (2) mechanical rasping with the radula, (3) a combination of both. Accordingly, boring mechanism of $L$. fortunei is associated with a chemo-mechanical theory of penetration in which abrasive action of the radula removes shell softened by secretion from the accessory boring organ (ABO). In case of the boring mechanism of $L$. fortunei in Naticidae, its main mechanism is formed by mechanical rasping with the radula. Therefore, we agree with Turner' opinion (1953) except for the part of his opinion associated with chemical acid components (secretions).

\section{ACKNOWLEDGEMENTS}

The author is grateful to Prof. Dr. Ki-Young Lee of Kunsan National University for helpful comments on the manuscript.

\section{REFERENCES}

Amio, M, (1963) A comparative embryology of marine gastropods, with ecological considerations. Bulletin of Shimonoseki University of Fisheries, 12: 229-358.

Carriker, M.R. 1943. On the structure and function of the proboscis in the common oyster drill, Urosalpinx cincre Say. Journal of Morphology, 73: 441-498.

Carriker, M.R. (1951) Observations on the penetration of tightly closing bivalves by Busicon and other predators. Ecology, 32: 73-84.

Carriker, M.R. (1961) Comparative functional morphology of boring mechanism of gastropods. American Zoologist, 1: 263-266.

Choi, K.C. (1962) Preliminary studies on the snails that bore the valves of young bivalves, Tapes philippinarum. Korean Journal of Zoology, 5: 9-12.

Colton, H.S. (1908) How Fulgur and Sycotypus eat oysters, mussels and clam, Proceeding of Academy Natural Science, Philadelphia, 60: 3-10.

Graham, A. 1941. The oesophagus of the stenoglossan prosobranchs. Proceedings of Royal Society of Edinburgh, 613: 1-22.

Fischer, F.H. (1922) Sur les gastropode perceurs. Journal of Conchyology, $67 \mathrm{pp}$.

Habe, T. (1969) A nomenclatorial note on Glossaulax 
didyma (Röding). Venus, 28: 109-111.

Hamada, S. 1961. Boring behaviour and Mechanism of a moon shell, Tectonatica janthostomoides. Tokai Regional Fisheries Research laboratory. Venus, 21: 212-217.

Higo, S.I., Callomon, P. and Goto, Y. (1999) Catalogue and biography of the marine shell-bearing mollusca of Japan. 215 pp. Elle Scientific Publications.

Hong S.Y., Park, K.Y., Par사, C.W., Han, C.H., Suh, H.L., Yun, S.G., Sung, C.B., Jo, S.G., Lim, H.S., Kang, Y.S., Kim, D.J., Ma, C.W., Son, M.H., Cha, H.K., Kim, K.B., Choi, S.D., Park, K,Y., Oh, C.W., Kim, D.N., Shon, H.S., Kim, J.N., Choi, J.H., Kim, M.H. and Choi, L.Y. Marine Invertebrates in Korean Coasts. Academy co. Seoul, Korea. 479pp.
Lee, J.J. 1969. Studies on the mortality of the young bivalves, Meretrix lusoria. (1) Boring rates of drills on the young bivalve, Meretrix lusoria. Bulletin of Korean Fisheries Society, 2: 63-70.

Kwon, O.K., Park, G.M. and LEE, J.S. (1993) Coloured Shells of Korea [in Korean]. Academy Publication Company, Seoul, 288 pp.

Min, D.K., Lee, J.S., Ko, D.B. and Je, J.G. (2004) Mollusks in Korea. Hanguel Graphics, Busan, Korea, 566 pp.

Pelseneer, P. (1925) Gastropodes marine carnivores Natica et Purpura. Annotation of Society of Royal Zoology, Belgique, 113 pp.

Turner, H.J. (1953) The driling mechanism of the Naticidae. Ecology, 34: 222-223. 